2014-03-27

\title{
Geographical limits to species-range shifts are suggested by climate velocity.
}

\author{
Burrows, MT
}

http://hdl.handle.net/10026.1/10115

10.1038/nature12976

Nature

All content in PEARL is protected by copyright law. Author manuscripts are made available in accordance with publisher policies. Please cite only the published version using the details provided on the item record or document. In the absence of an open licence (e.g. Creative Commons), permissions for further reuse of content should be sought from the publisher or author. 


\section{Geographical limits to species-range shifts are suggested by climate velocity}

Michael T. Burrows ${ }^{1}$, David S. Schoeman ${ }^{2}$, Anthony J. Richardson ${ }^{3,4}$, Jorge García Molinos ${ }^{1}$, Ary Hoffmann ${ }^{5}$, Lauren B. Buckley ${ }^{6}$, Pippa J. Moore ${ }^{7,8}$, Christopher J. Brown ${ }^{9}$, John F. Bruno ${ }^{6}$, Carlos M. Duarte ${ }^{10,11,12}$, Benjamin S. Halpern ${ }^{13,14}$, Ove Hoegh-Guldberg9, Carrie V. Kappel ${ }^{13}$, Wolfgang Kiessling ${ }^{15,16}$, Mary I. O’Connor ${ }^{17}$, John M. Pandolfi ${ }^{18}$, Camille Parmesan ${ }^{19,20}$, William J. Sydeman ${ }^{21}$, Simon Ferrier ${ }^{22}$, Kristen J. Williams ${ }^{22}$ \& Elvira S. Poloczanska ${ }^{3}$

The reorganization of patterns of species diversity driven by anthropogenic climate change, and the consequences for humans ${ }^{1}$, are not yet fully understood or appreciated ${ }^{2,3}$. Nevertheless, changes in climate conditions are useful for predicting shifts in species distributions at global $^{4}$ and local scales ${ }^{5}$. Here we use the velocity of climate change $e^{6,7}$ to derive spatial trajectories for climatic niches from 1960 to 2009 (ref. 7) and from 2006 to 2100 , and use the properties of these trajectories to infer changes in species distributions. Coastlines act as barriers and locally cooler areas act as attractors for trajectories, creating source and sink areas for local climatic conditions. Climate source areas indicate where locally novel conditions are not connected to areas where similar climates previously occurred, and are thereby inaccessible to climate migrants tracking isotherms: $16 \%$ of global surface area for 1960 to 2009, and 34\% of ocean for the 'business as usual' climate scenario (representative concentration pathway (RCP) 8.5) ${ }^{8}$ representing continued use of fossil fuels without mitigation. Climate sink areas are where climate conditions locally disappear, potentially blocking the movement of climate migrants. Sink areas comprise $1.0 \%$ of ocean area and $3.6 \%$ of land and are prevalent on coasts and high ground. Using this approach to infer shifts in species distributions gives global and regional maps of the expected direction and rate of shifts of climate migrants, and suggests areas of potential loss of species richness.

By reorganizing natural systems ${ }^{2}$, climate change is poised to be one of the greatest threats to biodiversity of this century ${ }^{3}$, compromising the integrity, goods and services of living systems ${ }^{1}$. Increased understanding of how species distributions and persistence are likely to be affected can inform effective conservation under climate change, as part of a range of considerations ${ }^{9}$. Predictions from complex models may incorporate ecological complexity but come with a high degree of uncertainty $^{10}$. A simpler approach is to consider the local speed and direction of shifting climate contours as an expectation of how species' distributions would have to shift to track the location of their thermal niches ${ }^{6,10}$. This is the velocity of climate change $e^{6,7}$ : the temporal trend divided by the spatial gradient in a climate variable such as temperature ${ }^{6}$ or precipitation ${ }^{10,11}$. Landscapes and seascapes have different patterns of climate velocity $^{7}$ and consequential residence times of climate, giving different implications for species' persistence and priorities for conservation ${ }^{12}$.
Patterns of shifts in distributions of many taxa in the ocean have already been shown to follow the velocity of climate ${ }^{5}$.

Here we use velocity-derived trajectories to indicate global regions susceptible to effects of geographical limits to climate-driven distribution shifts. Climate trajectories are paths that points on an isotherm will travel over specific periods (Fig. 1, see Methods for details), integrating spatially variable speeds and directions of climate velocity along the paths to show effects that static velocity maps cannot. Geographical limits to trajectories, either barriers such as coasts and mountains or lack of connections to cooler or warmer environments, suggest limits to climatic niche shifts and, by inference, species persistence at a local level or replacement from warmer environments (Figs 2 and 3). Velocity fields were derived for 1960-2009 for land and ocean surface temperatures $^{7}$ on a $1^{\circ}$ grid, allowing inference at a global scale, but sacrificing small-scale detail such as thermal minima on mountain tops or sharp gradients associated with ocean fronts ${ }^{13}$.

We categorized types of trajectory behaviour using trajectory length and the percentages of trajectories starting in, ending in and passing through cells (Fig. 1 and Extended Data Fig. 1). Short trajectories indicated non- or slow-moving thermal niches. Cells were classed as relative climate sinks if a high proportion of trajectories terminated there. Absolute climate sinks were also distinguished: coastal climate sinks where trajectories were blocked by coasts, and internal climate sinks where velocities in neighbouring cells converged. Cells were classed as climate sources if no trajectories ended there. Thereafter, cells with a high proportion of trajectories passing through were classed as corridors. Divergence cells were identified as those where fewer trajectories ended than started in that cell, and convergence cells if the opposite were true.

Uncertainty evaluated by resampling of annual average temperature maps gave a 'likely' ( $>66 \%$ ) consistency of designation of trajectory classes between bootstrap samples and the overall classification for 59\% of ocean and $72 \%$ of land cells (Fig. 2 and Extended Data Figs 2-4). Consistency was $<66 \%$ where spatial gradients and temperature trends are most uncertain, such as where inter- and multidecadal climate variability dominates as for the El Niño-Southern Oscillation in the tropical Pacific. Classification of 'very likely' (>90\%) was achieved for $40 \%$ of land and $26 \%$ of ocean cells, mainly sources, coastal sinks and low velocity areas (Extended Data Fig. 4).

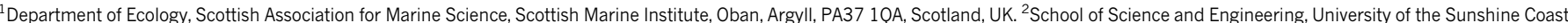

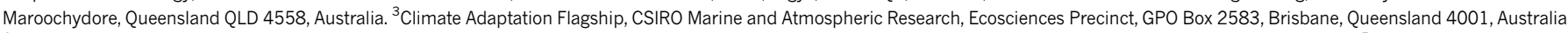

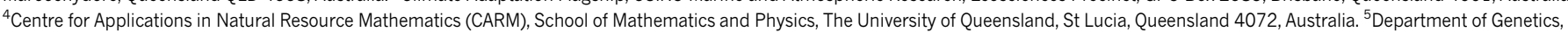

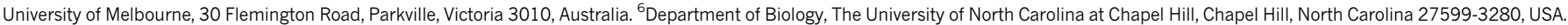

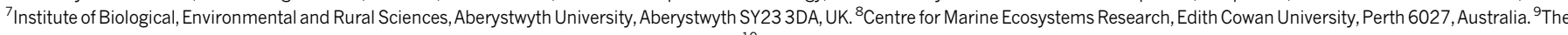

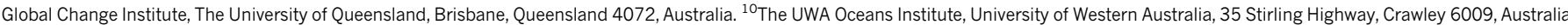

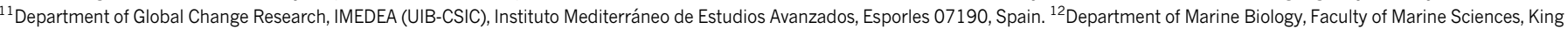

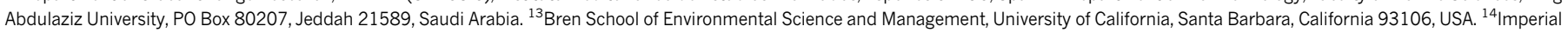

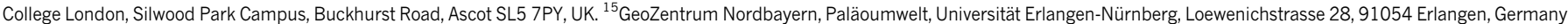

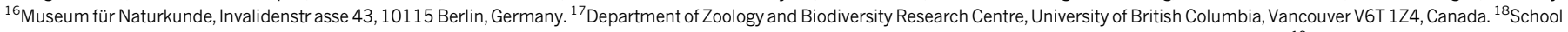

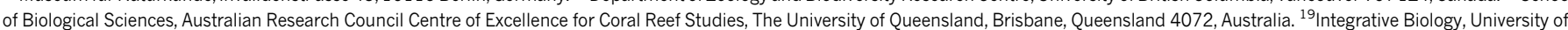

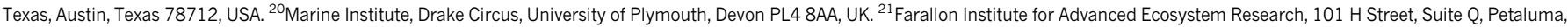
California 94952, USA. ${ }^{22}$ Climate Adaptation Flagship, CSIRO Ecosystem Sciences, GPO Box 1700, Canberra, Australian Capital Territory 2601, Australia. 
a
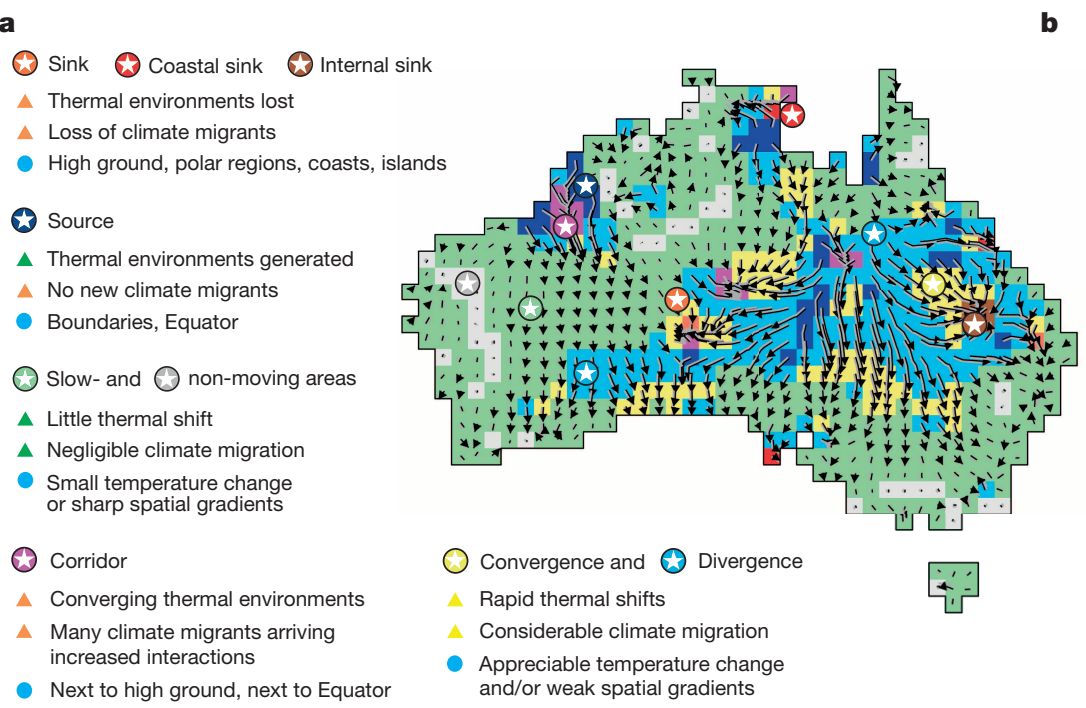

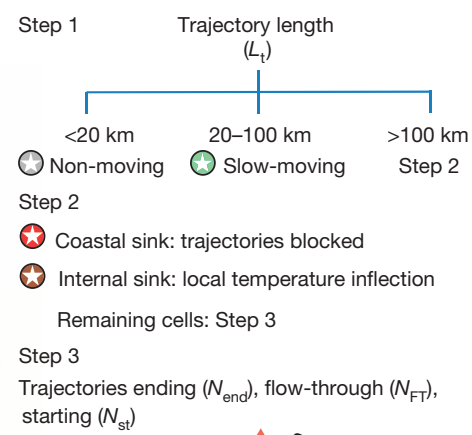
starting $\left(N_{\mathrm{st}}\right)$

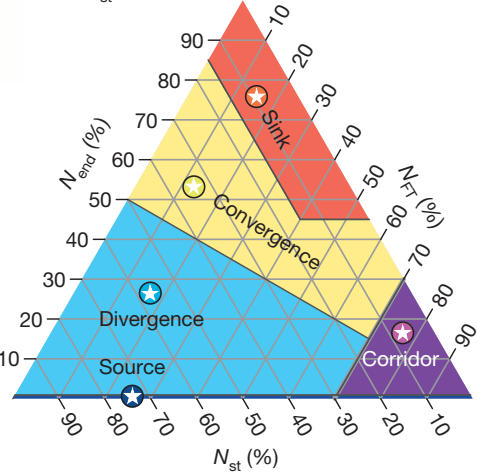

Figure $1 \mid$ Climate-change features emerging from the properties of climate velocity trajectories using the Australian landmass as an example.

a, Trajectories (indicated by arrows) show predicted 50-year (1960-2009) shifts based on isotherm velocity. Features described by trajectory properties are shown; typical locations and physical characteristics are indicated on the map (stars denoting typical locations of sinks, sources, corridors, convergence and

The proportions of land and sea areas classed as climate sources and sinks are similar at a global scale (sources: land $17.4 \%$, ocean $15.9 \%$; sinks: land 3.6\%, ocean 1.0\%), but the latitudinal pattern differs (Fig. 2 and Extended Data Figs 5-9 for regional maps). For ocean surface temperatures, climate sources are concentrated within $10^{\circ}$ latitude of the Equator (Figs 2b, d), a pattern not evident on land (Fig. 2a, c). divergence, and slow- and non-moving areas). The respective implications of these physical characteristics for climate migrants are listed in the boxes (triangles). b. Hierarchical sequential classification of climate change features based on length of trajectories (step 1), geographical features (step 2) and the relative abundance of trajectories ending in, starting from and flowing through each cell (step 3).

Topographic complexity on land generates more local warm and cold source and sink areas compared to the ocean. Importantly, $12.0 \%$ of land trajectories and $5.4 \%$ of ocean trajectories terminate in sinks, representing 'lost' local conditions: 6.1\% (5.0\%) land (ocean) ending in coastal sinks, $5.9 \%(0.4 \%)$ in internal sinks. These losses are analogous to 'disappearing climates ${ }^{\text {'14 }}$ but here result from local connections
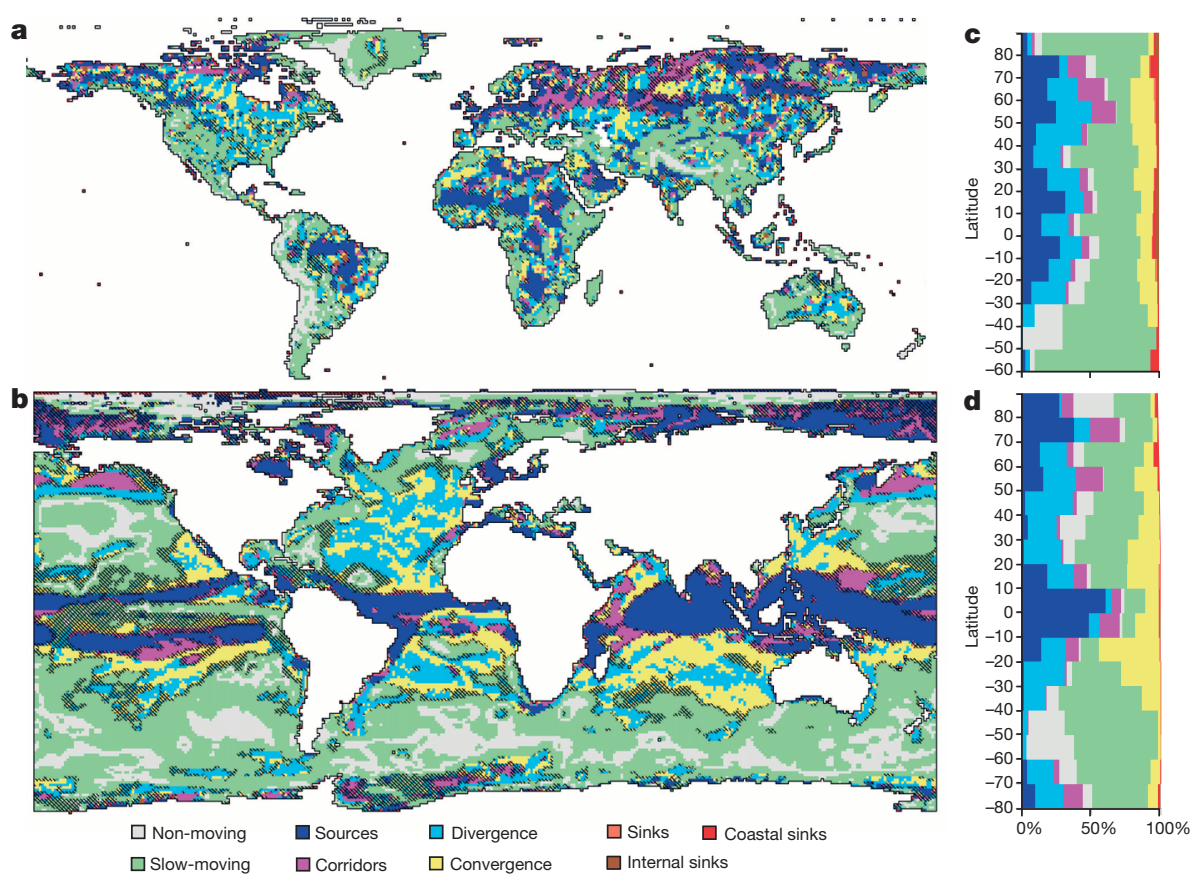

Figure $2 \mid$ Global patterns of climate trajectory classes. a-d, On land (a) and in the ocean (b), and proportional areas by latitude (c, d). Uncertainty in classification of areas is shown by the cross hatching on (a, c): $<66 \%$ of 500 bootstrap class maps consistent with underlying class map. Non-hatched areas have classification that is 'likely' ( $>66 \%$ consistent). Uncertainty between convergence and divergence areas and slow and non-moving areas is not shown (see Extended Data Fig. 2). 

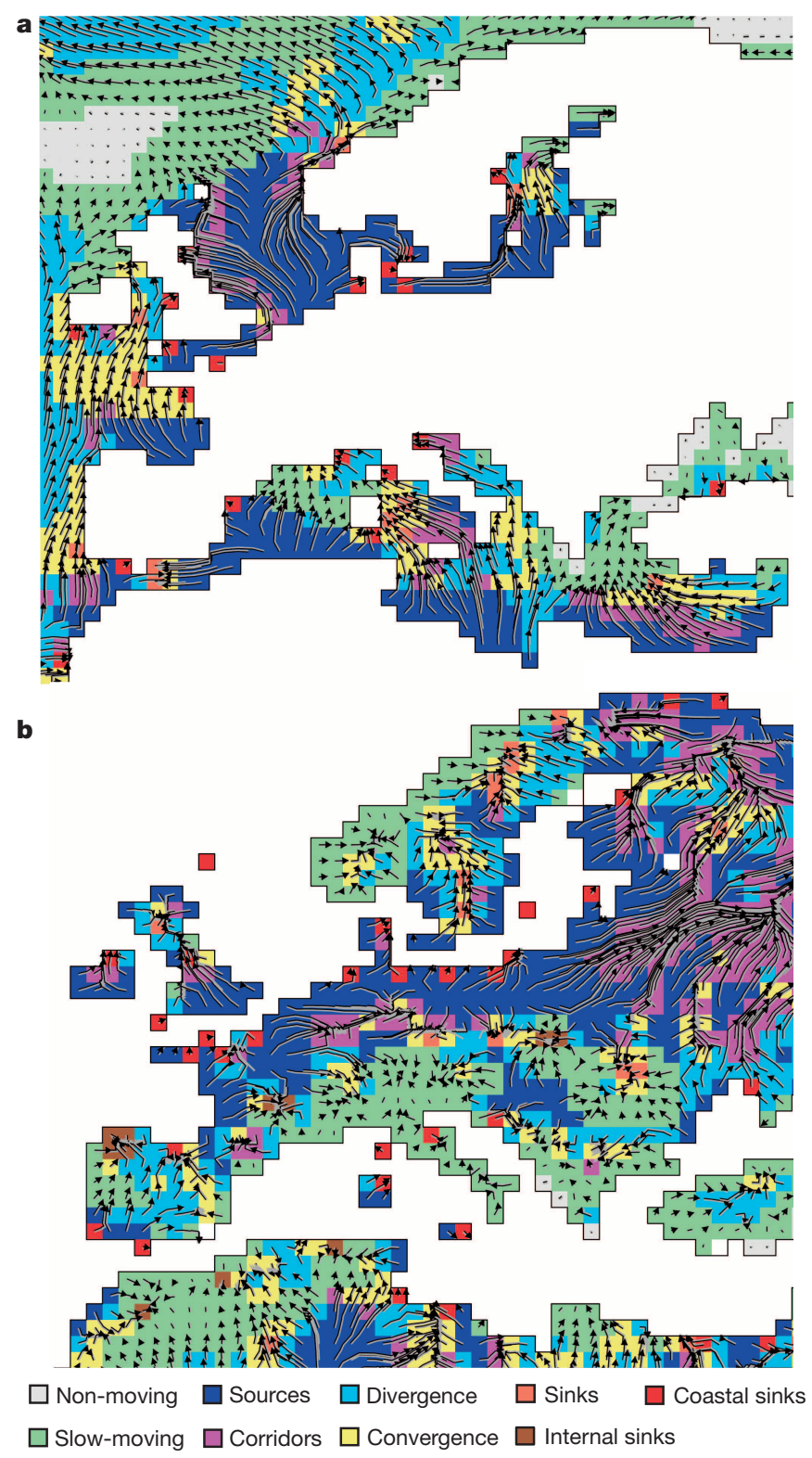

Figure 3 Regional patterns of climate velocity trajectory classes for land and sea surface temperatures. a, b, We show 50 -year trajectories (shown by arrows) of climates (1960-2009) for Europe for $1^{\circ}$ grid cells, overlaid on climate trajectory classes for ocean (a) and land (b).

to thermal minima rather than global loss of combinations of climatic conditions.

In the ocean, coastal sources form where poleward trajectories depart from coastlines, as in North Africa, and coastal sinks where equatorward coastlines block trajectories, as in southern France (Fig. 3a). The opposite occurs on land to a degree: sources on equatorward coastlines and sinks along poleward coastlines. However, cooler, higher regions of continents, such as mountain ranges in Europe, 'attract' trajectories towards the interior, disrupting the otherwise-poleward flow, resulting in internal sinks at greater elevations (Fig. 3b). Elevated land is also more likely to comprise non- or slow-moving areas. Corridors are evident in areas of convergent trajectories and high climate velocities, as in the northern North Sea and in southern Germany (Fig. 3a, b).

Future climate trajectories for sea surface temperature (SST) using an example global climate model (ACCESS1.0) for 2006-2100 produce similar patterns of shifting climates to those seen globally for 19602009. Sources were indicated at thermal maxima around the equator (Fig. 4a, c). Greater warming in the RCP 8.5 'business as usual' scenario ${ }^{8}$ $\left(2.95^{\circ} \mathrm{C}\right.$ increase in annual average SST for $2080-2099$ over $\left.1960-2009\right)$ results in longer trajectories than the RCP 4.5 scenario run $\left(1.75^{\circ} \mathrm{C}\right.$ increase) and a doubling in size of areas identified as sources (RCP 8.5, $34.1 \%$ of scenario cells as sources versus $19.8 \%$ for RCP 4.5 ). Localscale patterns were also similar (Fig. $4 \mathrm{~b}$, d), as thermal gradients that determine trajectory direction are reproduced in the climate models. No-analogue climate futures ${ }^{15}$ will emerge in source areas with novel climates ${ }^{14}$, particularly around the equator, but not in sources that result from coastal barriers disconnected from similar climates elsewhere.

Each climate trajectory feature has different implications for the migration patterns of climate-sensitive species through climate connectivity (Extended Data Table 1). Species richness in climate source areas may decline, because climate migrants leaving may not be replaced: sources lack connection routes for new migrants. Converging temperature isotherms in relative climate sinks may concentrate climate migrants, increasing local diversity, whereas absolute climate sinks represent climatic dead-ends where species cannot spread along thermal gradients into cooler areas, creating potential for local extinction. Large numbers of trajectories traversing a limited pathway suggest important corridors for climate migrants.

Patterns of distribution shifts indicated by trajectory behaviour raise questions for ecology and conservation of climate-sensitive species ${ }^{12}$, particularly when considered alongside the magnitude and latitude of
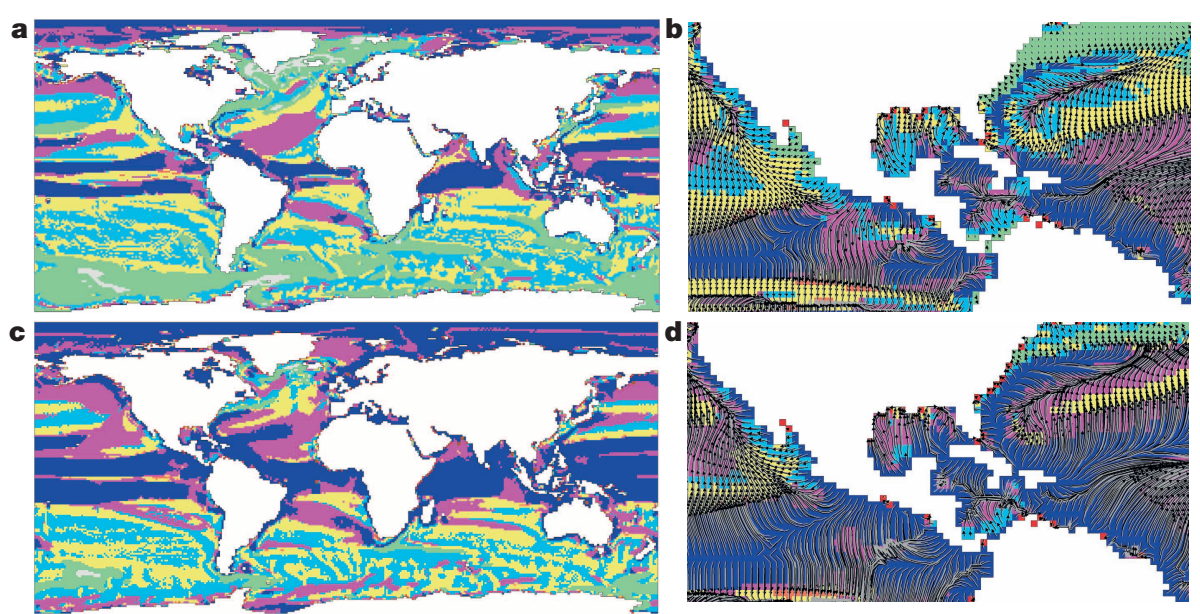

$\square$ Non-moving $\square$ Sources $\square$ Divergence

$\square$ Slow-moving

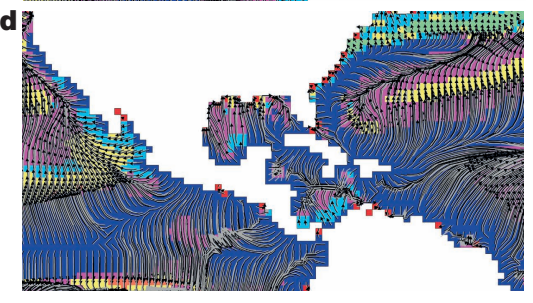

$\square$ Sinks $\quad \square$ Coastal sinks

$\square$ Internal sinks
Figure 4 Global and regional patterns of 50-year climate trajectory classes based on trends from ensembles of global climate models for 2006-2100. a-d, Classes for two CMIP5 scenarios: the $4.5 \mathrm{~W}$ $\mathrm{m}^{-2}$ (RCP 4.5) scenario $(\mathbf{a}, \mathbf{b})$ and the $8.5 \mathrm{~W} \mathrm{~m}^{-2}$ (RCP 8.5) scenario (c, d), derived from temperature trends and spatial patterns in temperature in data from the ACCESS1.0 CMIP5 global climate model. Arrows show the expected shift in location of points along isotherms over a 50 -year period. 
climate change ${ }^{16}$. Long 'climate residence times' in areas of low velocity ${ }^{10}$ have been associated with high levels of historical endemism ${ }^{17}$ and have led to such areas being proposed as genetic and evolutionary refugia ${ }^{18}$. The non-replacement of climate migrants in climate source areas may result in net loss of species richness, and facilitate the establishment of new species into abandoned niches ${ }^{19}$, such as in the eastern Mediterranean Sea via the Suez $\mathrm{Canal}^{20}$. A larger number of inbound climate migrants in convergent areas, corridors and sinks implies that local communities should face greater reshuffling of species and novel ecological interaction $\mathrm{s}^{21}$, and compromised genetic diversity through gene swamping ${ }^{22}$ but with increased adaptive gene flow ${ }^{23}$. Climate migrants face local extinction in climate sink areas, unless the species involved can adapt to changed conditions.

Climate velocity is emerging as a good predictor for range shifts in the ocean ${ }^{4,5}$, whereas the relationship is still to be investigated on land, although terrestrial species distribution shifts have been related to latitudinal shifts in isotherms ${ }^{24}$. The similarity in trajectory maps of future projections with past reconstructions suggests that the ecological implications and therefore the management actions for conserving biodiversity, as informed by current climate trajectories, could remain effective into the future. Species losses from both source and sink areas may accelerate with climate change, with greater warming resulting in areas of novel and lost climates, suggesting that impacts may be greatest in these areas. The approach developed here offers a rapid global method to quantify and map patterns of shifting thermal niches, and by implication those species tracking thermal conditions, and highlights those areas of the globe that may be at risk from the effects of geographical barriers to climate migrants.

\section{METHODS SUMMARY}

Velocity fields were derived for 1960-2009 land and ocean surface temperatures using Hadley Centre HadISST v1.1 and Climate Research Unit CRU TS3.1 (ref. 7) data sets, and for global climate model (GCM) projections for 2006-2100 using example GCM model data from CMIP5 (Coupled Model Intercomparison Project Phase 5) experiments for RCP 4.5 and RCP 8.5 scenarios. Velocity was calculated by dividing the 50 -year temperature trend by the spatial gradient in 50 -year means, taking the direction from the spatial gradient ${ }^{6}$. Trajectories of climate were obtained by calculating displacements using local velocity. If trajectories hit a coastal barrier and a cooler or warmer cell was found locally then the trajectory continued towards that cell, else the cell was designated as a coastal sink.

The collective behaviour of trajectories was obtained from $0.1^{\circ}$-spaced trajectories projected over 50 years at 0.1 -year intervals. Cells were classed (Fig. 1b) as: first, slow or non-moving where 50 -year trajectories were less than $100 \mathrm{~km}$; second, coastal and internal sinks, where trajectories halted on coastlines or converged towards a central point; third, five types based on proportions of trajectories starting from, ending in, and flowing through cells. These five types of cells are: sources, cells where no trajectories ended; sinks where many trajectories ended; corridors, cells with a high proportion of trajectories passing through; and divergence and convergence cells as those where fewer/more trajectories ended than started in that cell.

Uncertainty of classification into areas based on trajectory behaviour was estimated using bootstrap resampling $(n=500)$ of the temperature data sets. Each bootstrap sample comprised a random selection with replacement of 50 annual mean temperatures from the original series, from which mapped temporal and spatial temperature trends, and thereby velocity, were calculated. 50 -year trajectories based on these maps gave a bootstrap classification of trajectory areas. Consistency of types by grid cell was expressed as the percentage of cells in bootstrap maps that were the same type as the original classification.

Online Content Any additional Methods, Extended Data display items and Source Data are available in the online version of the paper; references unique to these sections appear only in the online paper.

\section{Received 13 September; accepted 30 December 2013. \\ Published online 9 February; corrected online 26 March 2014 (see full-text HTML version for details).}

1. Cardinale, B. J. et al. Biodiversity loss and its impact on humanity. Nature $\mathbf{4 8 6}$, 59-67 (2012)
2. Barnosky, A. D. et al. Approaching a state shift in Earth's biosphere. Nature 486, 52-58 (2012).

3. Pereira, H. M. et al. Scenarios for global biodiversity in the 21st century. Science 330, 1496-1501 (2010).

4. Poloczanska, E. S. et al. Global imprint of climate change on marine life. Nature Climate Change 3, 919-925 (2013).

5. Pinsky, M. L., Worm, B., Fogarty, M. J., Sarmiento, J. L. \& Levin, S. A. Marine taxa track local climate velocities. Science 341, 1239-1242 (2013).

6. Loarie, S. R. et al. The velocity of climate change. Nature 462, 1052-1055 (2009).

7. Burrows, M. T. et al. The pace of climate change in marine and terrestrial ecosystems. Science 334, 652-655 (2011).

8. Taylor, K. E., Stouffer, R. J. \& Meehl, G. A. An overview of CMIP5 and the experiment design. Bull. Am. Meteorol. Soc. 93, 485-498 (2012).

9. Dawson, T. P., Jackson, S. T., House, J. I., Prentice, I. C. \& Mace, G. M. Beyond predictions: biodiversity conservation in a changing climate. Science $\mathbf{3 3 2}, 53-58$ (2011).

10. Ackerly, D. D. et al. The geography of climate change: implications for conservation biogeography. Divers. Distrib. 16, 476-487 (2010).

11. Ordonez, A. \& Williams, J. W. Projected climate reshuffling based on multivariate climate-availability, climate-analog, and climate-velocity analyses: implications for community disaggregation. Clim. Change 119, 659-675 (2013).

12. Gillson, L., Dawson, T. P., Jack, S. \& McGeoch, M. A. Accommodating climate change contingencies in conservation strategy. Trends Ecol. Evol. 28, 135-142 (2013).

13. Dobrowski, S. Z. et al. The climate velocity of the contiguous United States during the 20th century. Glob. Chang. Biol. 19, 241-251 (2013).

14. Williams, J. W., Jackson, S. T. \& Kutzbach, J. E. Projected distributions of novel and disappearing climates by 2100 AD. Proc. Natl Acad. Sci. USA 104, 5738-5742 (2007).

15. Williams, J. W. \& Jackson, S. T. Novel climates, no-analog communities, and ecological surprises. Front. Ecol. Environ. 5, 475-482 (2007).

16. Deutsch, C. A. et al. Impacts of climate warming on terrestrial ectotherms across latitude. Proc. Natl Acad. Sci. USA 105, 6668-6672 (2008).

17. Sandel, B. et al. The influence of late Quaternary climate-change velocity on species endemism. Science 334, 660-664 (2011).

18. Budd, A. F. \& Pandolfi, J. M. Evolutionary novelty is concentrated at the edge of coral species distributions. Science 328, 1558-1561 (2010).

19. Facon, B. et al. A general eco-evolutionary framework for understanding bioinvasions. Trends Ecol. Evol. 21, 130-135 (2006).

20. Hiddink, J. G., Ben Rais Lasram, F., Cantrill, J. \& Davies, A. J. Keeping pace with climate change: what can we learn from the spread of Lessepsian migrants? Glob. Chang. Biol. 18, 2161-2172 (2012).

21. Parmesan, C. \& Yohe, G. A globally coherent fingerprint of climate change impacts across natural systems. Nature 421, 37-42 (2003).

22. Norberg, J., Urban, M. C., Vellend, M., Klausmeier, C. A. \& Loeuille, N. Ecoevolutionary responses of biodiversity to climate change. Nature Climate Change $\mathbf{2}$, 747-751 (2012).

23. Sgrò, C. M., Lowe, A. J. \& Hoffmann, A. A. Building evolutionary resilience for conserving biodiversity under climate change. Evol. Appl. 4, 326-337 (2011).

24. Chen, I. C., Hill, J. K., Ohlemüller, R., Roy, D. B. \& Thomas, C. D. Rapid range shifts of species associated with high levels of climate warming. Science 333, 1024-1026 (2011).

Acknowledgements This work was conducted as a part of the Towards Understanding Marine Biological Impacts of Climate Change Working Group supported by the National Center for Ecological Analysis and Synthesis, a center funded by the NSF (grant no. EF-0553768), the University of California, Santa Barbara and the State of California. M.T.B., P.J.M. and J.G.M. were supported by the UK Natural Environment Research Council grant NE/J024082/1. D.S. was supported by the Australian Research Council's Collaborative Research Network. J.P. thanks the Australian Research Council Centre of Excellence for Coral Reef Studies for additional support, and A.J.R. was supported by the Australian Research Council Discovery Grant DP0879365 and Future Fellowship Grant FT0991722.

Author Contributions M.T.B., D.S.S., A.J.R. and E.S.P. conceived the research. M.T.B., J.G.M. and D.S.S. analysed the data. M.T.B., D.S.S., A.J.R., E.S.P., J.G.M. and M.I.O. wrote the first draft. M.T.B., D.S.S., A.J.R., J.G.M., A.H., L.B.B., P.J.M., C.J.B., J.F.B., C.M.D., B.S.H., O.H.G., C.V.K.,W.K., M.I.O., J.M.P., C.P., W.J.S., S.F., K.J.W. and E.S.P. contributed equally to discussion of ideas and analyses, and all authors commented on the manuscript.

Author Information Data used in analyses are available from the University of East Anglia Climate Research Unit and the UK Meteorological Office Hadley Centre, with online access at the British Atmospheric Data Centre. Maps are available as Google Earth files on http://www.figshare.com. Reprints and permissions information is available at www.nature.com/reprints. The authors declare no competing financial interests. Readers are welcome to comment on the online version of the paper. Correspondence and requests for materials should be addressed to M.T.B. (mtb@sams.ac.uk). 


\section{METHODS}

Data sets and calculation of velocity. Velocity fields were derived for the period 1960-2009 for the ocean using the Hadley Centre sea surface temperature data set HadISST v1.1 and for land with the Climate Research Unit CRU TS3.1 (ref. 7). Velocity was calculated for $1^{\circ}$ grid cells by dividing the local 50 -year trend in temperature (from linear regression) in ${ }^{\circ} \mathrm{C}$ per yr by the spatial gradient in ${ }^{\circ} \mathrm{C}$ per $\mathrm{km}$, and angles were derived from the direction of the spatial gradient ${ }^{6}$. We also calculated velocity fields for sea surface temperature from global climate model projections for 2006-2100. We aimed to use ensemble-average data from CMIP5 experiments ${ }^{8}$ RCP 4.5 and RCP 8.5 , scenarios with approximate radiative forcing of 4.5 and $8.5 \mathrm{~W} \mathrm{~m}^{-2}$, projected onto the same $1^{\circ}$ grid coordinates as the HadISST data. However, differences in grid resolution produced artefacts at coastal margins for ensemble means, so model runs from a single model, the CSIRO ACCESS1.0 model, were used instead. Long-term trends and averages for each $1^{\circ}$ cell were calculated for the 95 years of scenario data, and used to calculate velocity in the same way as for HadISST data.

Calculating trajectories. We produced trajectories of climate for 1960-2009, and for a 50-year period based on trends and patterns from global climate models for the period from 2006-2100, by forward iteration of climate locations through velocity fields with speed $V$ and direction $\theta$. Displacement at each time step was determined from local grid-cell speed and direction to give shifts in $\mathrm{km}$ in $x$ and $y$ directions $(\Delta x=V \sin (\theta)$ and $\Delta y=V \cos (\theta))$. The proposed new grid location was then converted back to latitude and longitude (Longitude $+\Delta x / 111.325^{*}$ $\cos ($ latitude) and Latitude $+\Delta y / 111.325)$. A short time interval (0.1 year) was used to minimise the incidence of displacements spanning more than one grid cell. This occurred only where velocity values exceeded $1000 \mathrm{~km} \mathrm{yr}^{-1}$, affecting 50 of 16,752 grid cells on land ( $0.3 \%$ ) and 451 of 42,974 cells (1.04\%) in the ocean, and in these cases displacements were limited to $1^{\circ}$ latitude or longitude. If new locations fell on land or ocean, such that a coastal barrier or pole was not encountered, then that location became the starting point for the next calculation. If the proposed location were beyond a land or sea barrier, a search began for the immediate nondiagonal neighbour cell in the same medium: with the lowest (highest) temperature if velocity was positive (negative). If a cooler or warmer cell was found then the trajectory was moved along in the direction to that cell $(\varphi)$ at a speed given by $(V / \cos (\varphi-\theta))$, and limited to a maximum displacement of $1^{\circ}$ of latitude or longitude. If the search was not successful, such that the focal cell was the warmest or coolest in its local neighbourhood, or the trajectory went beyond either pole, then the trajectory was halted and the cell was designated as a coastal sink. This approach allowed trajectories to flow realistically along coastlines and around islands.

Collective behaviour of trajectories. The collective grid-scale behaviour of trajectories was investigated by starting 100 trajectories at $0.1^{\circ}$ intervals in each grid cell across the globe, separately for the land and ocean velocity fields, and projecting locations forwards for 50 years at 0.1 -year intervals. Our trajectory classification followed three hierarchical sequential steps (Fig. 1b).
First, cells were first identified as slow or non-moving climate cells where the length of velocity trajectories over a 50-year simulation period $\left(L_{\mathrm{t}}\right)$ spanned less than the approximate dimensions of a single cell $\left(L_{\mathrm{t}}<100 \mathrm{~km}\right)$. The boundary limit between non- and slow-moving was set at $L_{\mathrm{t}}<20 \mathrm{~km}$ (that is, $<4 \mathrm{~km}$ per decade).

The second step involved the identification of coastal and internal sinks. Coastal sinks captured the potential cul-de-sac effect imposed by continental margins on climate migrants where climate trajectories hit the land (or the ocean for terrestrial trajectories) and no cooler (warmer) neighbouring cells are available to move to under a warming (cooling) climate. We defined internal climate sinks based on trajectory velocity angles as areas where thermal gradients in neighbouring cells converge towards their central point of intersection.

For the third step, the remaining cells were finally classified by reference to the total number of trajectories per cell based on the proportions of three variables: the number of trajectories starting from $\left(N_{\text {st }}\right)$, ending in $\left(N_{\text {end }}\right)$, and flowing through $\left(N_{\mathrm{FT}}\right)$ a cell during the period. Although the number of trajectories starting is constant for a given trajectory resolution (100 starting trajectories for a $0.1^{\circ}$ resolution), its proportion changes in relation to the other two variables and, together with that of trajectories ending in a cell, indicates the degree to which an area releases (receives) climates shifting to (from) other areas. Similarly, the proportion of trajectories flowing through a cell gives an index of the flux of climate conditions through that cell. Based on the relative magnitude of these three variables, we subsequently described collective trajectory cell behaviour by dividing the 'trajectory space' into five classes using a ternary plot (Fig. $1 \mathrm{~b}$ and Extended Data Fig. 1): climate sources, when no trajectories ended in a cell $\left(\% N_{\text {end }}=0\right)$; relative climate sinks, when the relative number of trajectories ending in a cell was high and the proportion of starting trajectories was low $\left(\% N_{\text {end }}>\right.$ $\left.45 \%, \% N_{\mathrm{st}}<15 \%\right)$; and corridors as cells with a high proportion of trajectories passing through $\left(\% N_{\mathrm{FT}}>70 \%, \% N_{\text {end }}>0\right)$. Finally, divergence and convergence cells were identified respectively as those where fewer/more trajectories ended than started in that cell.

Evaluation of uncertainty in trajectory area classes. Uncertainty of classification into areas based on trajectory behaviour was estimated using bootstrap resampling of the 1960-2009 HadISST 1.1 and CRU TS 3.1 data sets. For each bootstrap sample, 50 years were randomly selected with replacement from the period. The corresponding yearly global maps of annual means were used to calculate bootstrap maps of temporal and spatial trends in temperature, and thereby velocity. Classification of 50-year trajectories based on these maps therefore gave a bootstrap realization based on variability in temporal trends, and directions and magnitudes of the spatial gradients in temperature (Extended Data Fig. 2). The bootstrap process was repeated 500 times. Consistency of area classifications was expressed as the percentage of cells in bootstrap maps that were the same as the original maps based on all the 1960-2009 data. 
a

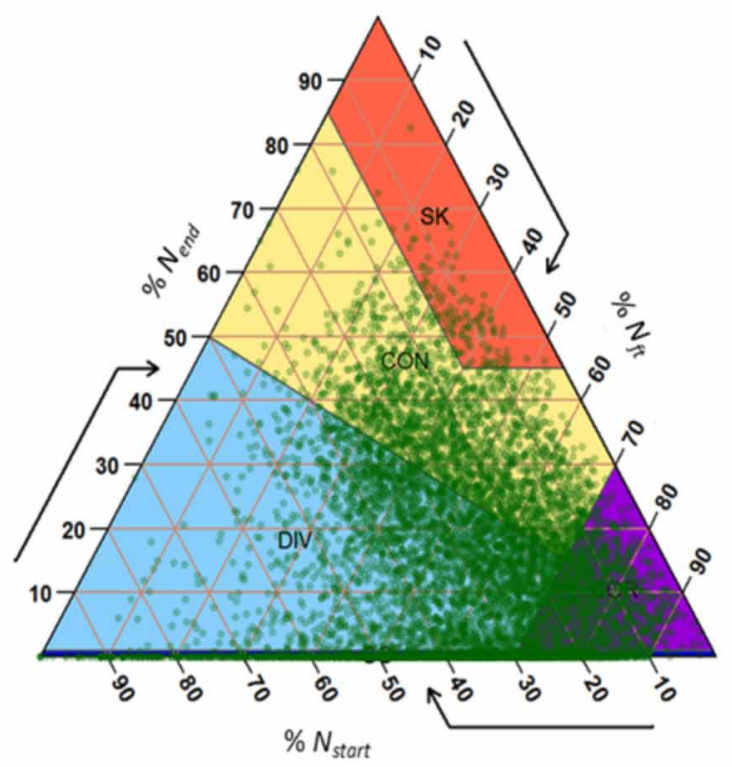

c

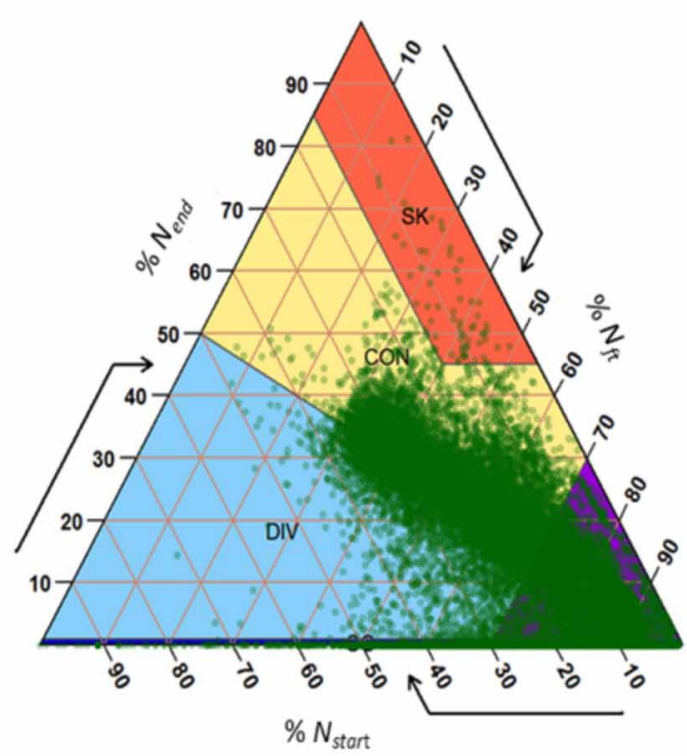

Extended Data Figure $1 \mid$ Ternary plots containing the trajectory classes. a-d, Plots are based on the proportions of trajectories starting from $\left(N_{\mathrm{st}}\right)$, ending in $\left(N_{\text {end }}\right)$, and flowing through $\left(N_{\mathrm{FT}}\right)$ a cell. In a ternary plot three-dimensional cell coordinates (adding up to a $100 \%$ ) are projected in a two-dimensional space. The arrows by the axes indicate the direction in which

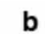

SST

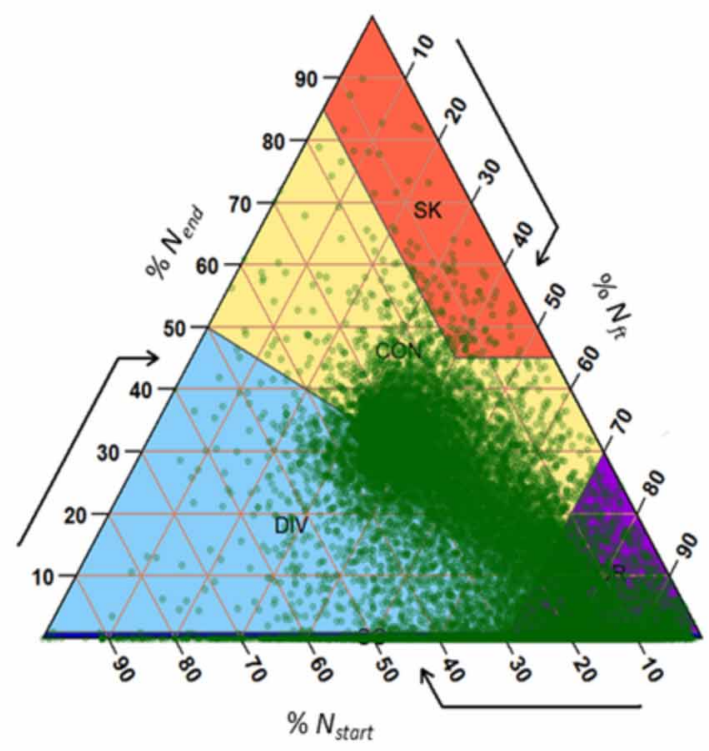

d

RCP 4.5

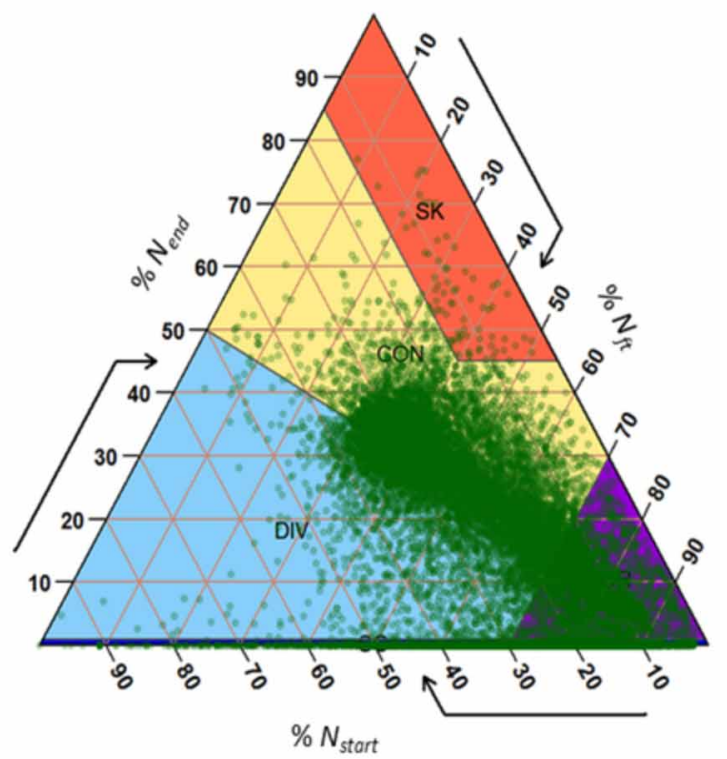

each variable is projected into the trajectory space. Point clouds represent global $1^{\circ}$ resolution cell coordinate projections into the trajectory space based on 50 -year climate trajectory simulations for land (a) and sea surface temperature (b) (1960-2009), and 2006-2100 RCP 8.5 (c) and RCP 4.5 (d) climate scenarios for ocean temperatures. CON, convergence; DIV, divergence; SK, relative sink. 
a

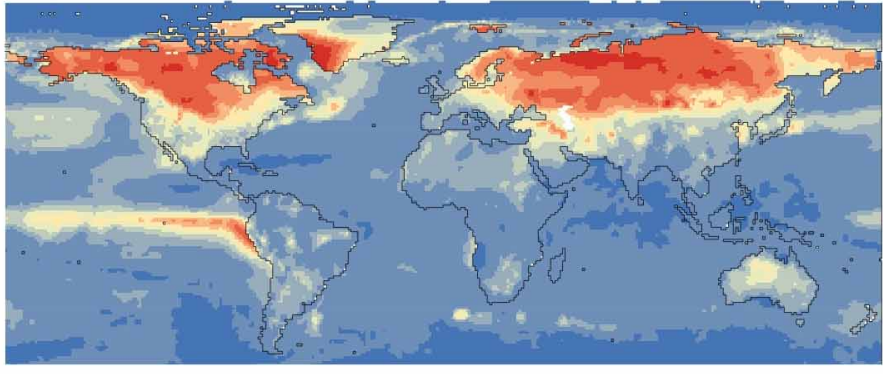

b

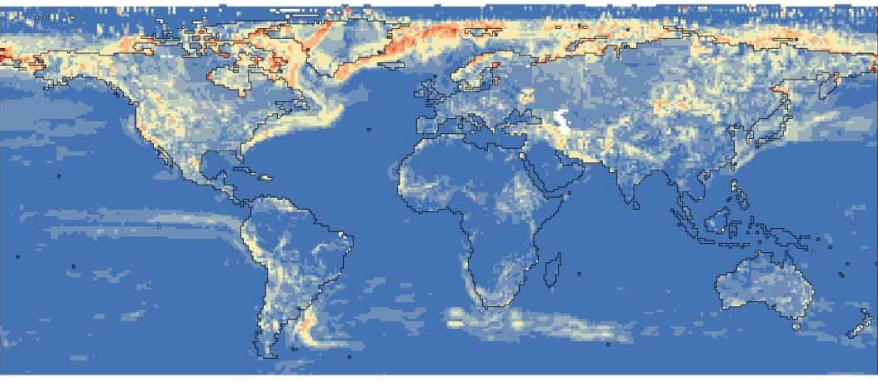

Standard Error

trend $\left(\mathrm{C} \mathrm{yr}{ }^{-1}\right)$

$0.00014-0.002$

$0.002-0.004$

$0.004-0.005$

$0.005-0.006$

$0.006-0.007$

$0.007-0.008$

$0.008-0.009$

$0.009-0.01$

$0.01-0.012$

$0.012-0.016$

Standard Deviation spatial gradient $\left(\mathrm{C} \mathrm{km}^{-1}\right)$

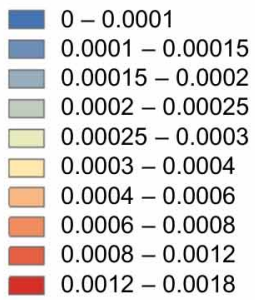

Angular deviation (rad)

c

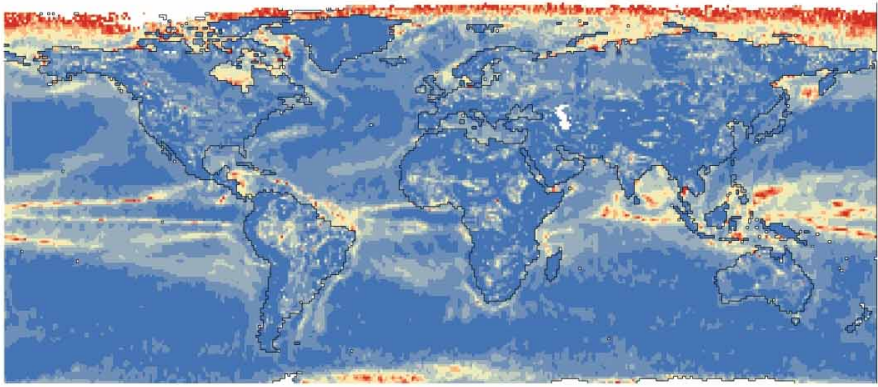
$0-0.015$
$0.015-0.03$
$0.03-0.06$
$0.06-0.1$
$0.1-0.15$
$0.15-0.25$
$0.25-0.4$
$0.4-0.5$
$0.5-0.75$
$0.75-1.2$

d

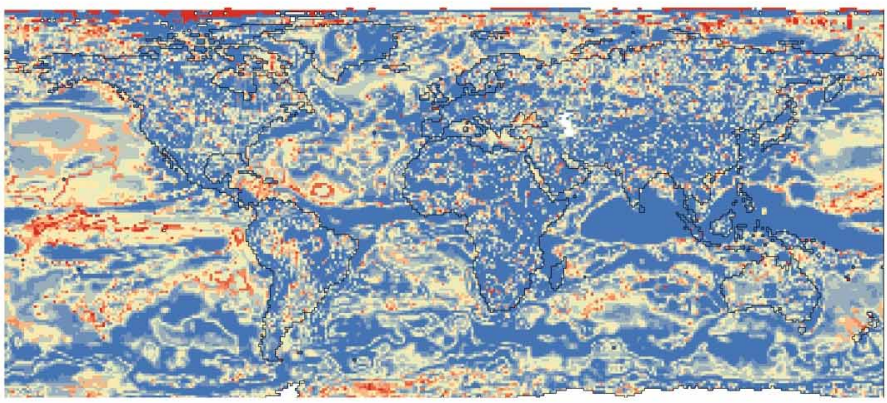

Proportion coincident classes (\%)

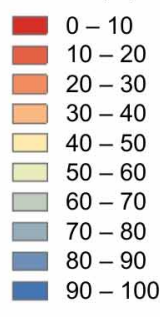

e

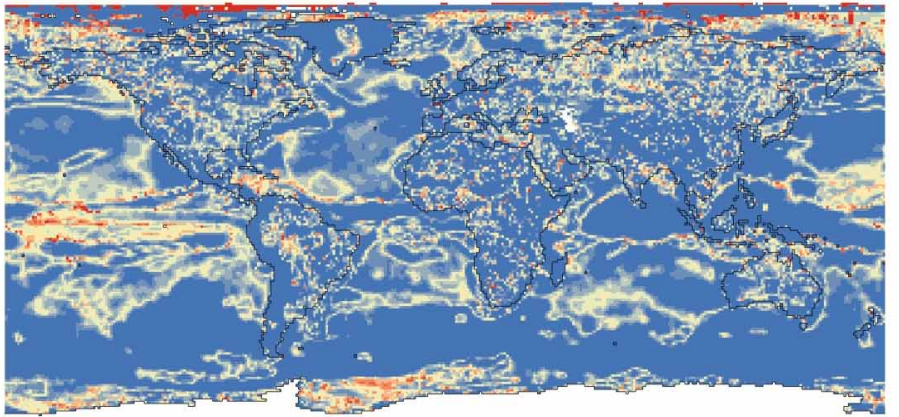

Proportion coincident classes (\%)

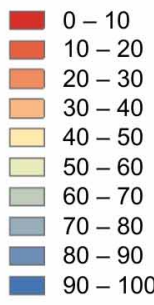

Extended Data Figure $2 \mid$ Uncertainty associated with the proposed

trajectory classification. a, Mean standard error of the trend. b, Standard deviation in magnitude of spatial gradient. c, Angular deviation of the spatial gradient associated to bootstrapped $(n=500)$ mean annual surface temperature series. d, e, Bootstrap-derived uncertainty associated with the proposed trajectory classification (d) and after collapsing slow/non-moving and convergence/divergence areas into a single category each (e). rad, radians. 
a

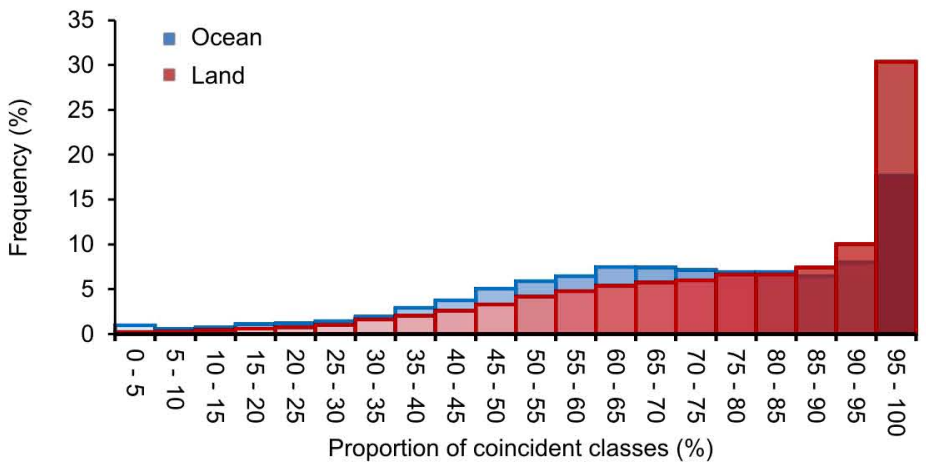

b

C

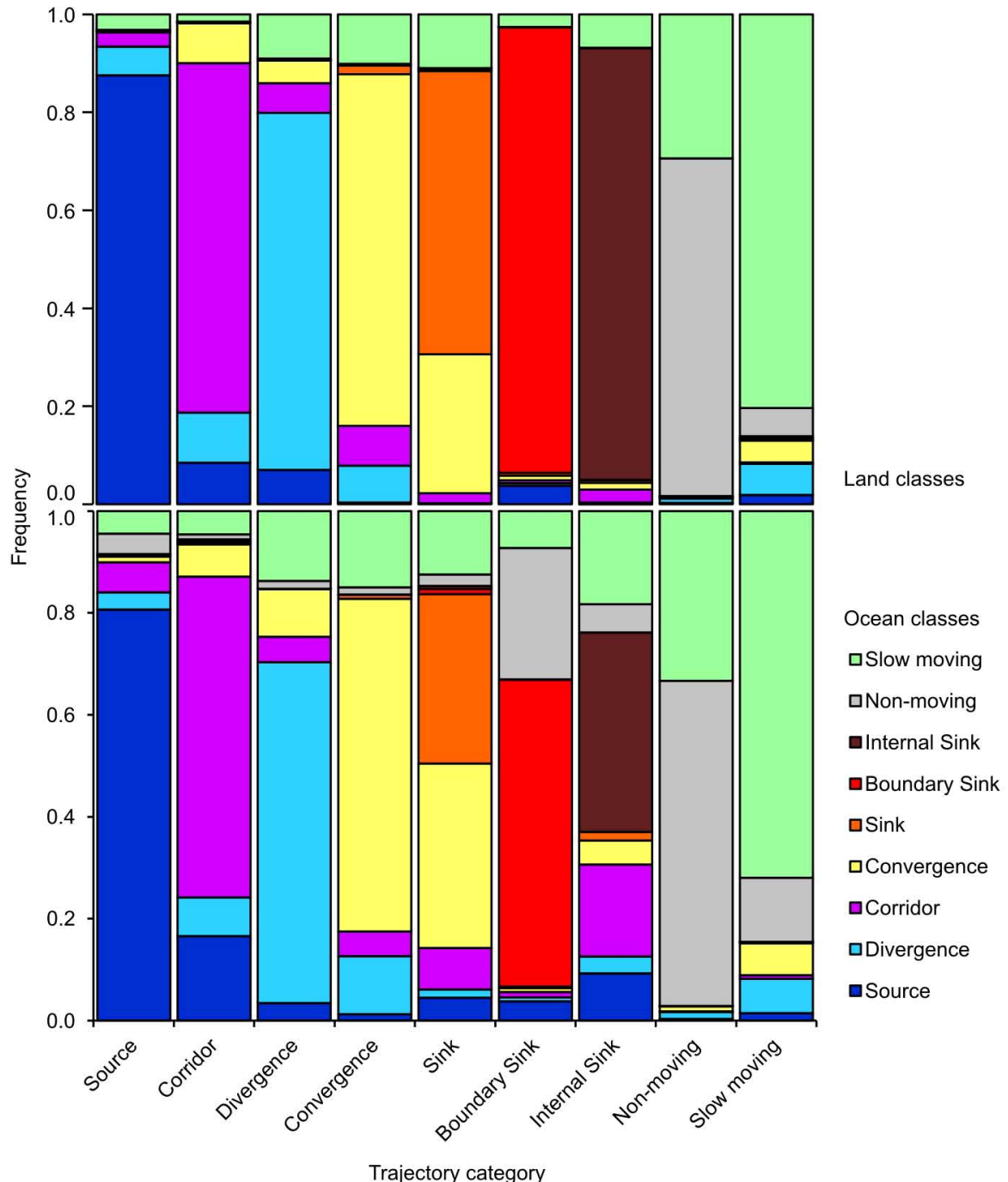

Extended Data Figure 3 Frequency distribution of the uncertainty associated with the trajectory-based classification of land and ocean.

a, Frequency histogram of the proportion of coincident categories between the proposed 1960-2009 trajectory classification and classifications resulting from
500 bootstrapped surface temperature climate series (see Methods for details). b, $\mathbf{c}$, Cumulative frequency plots of the mean distribution of bootstrapped trajectory categories contained in each category of the proposed trajectory classification for land (b) and ocean regions (c). 
a
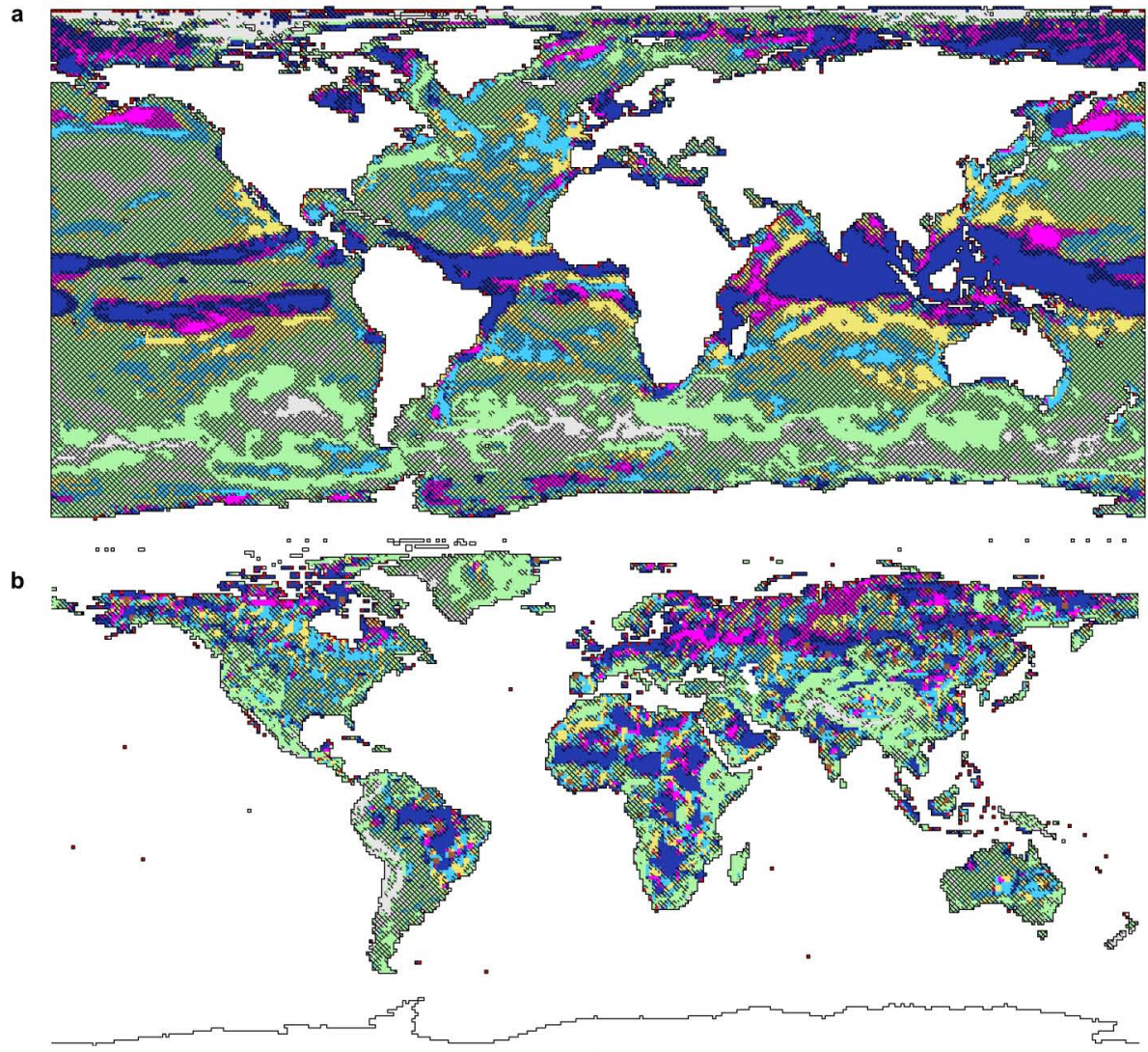

c

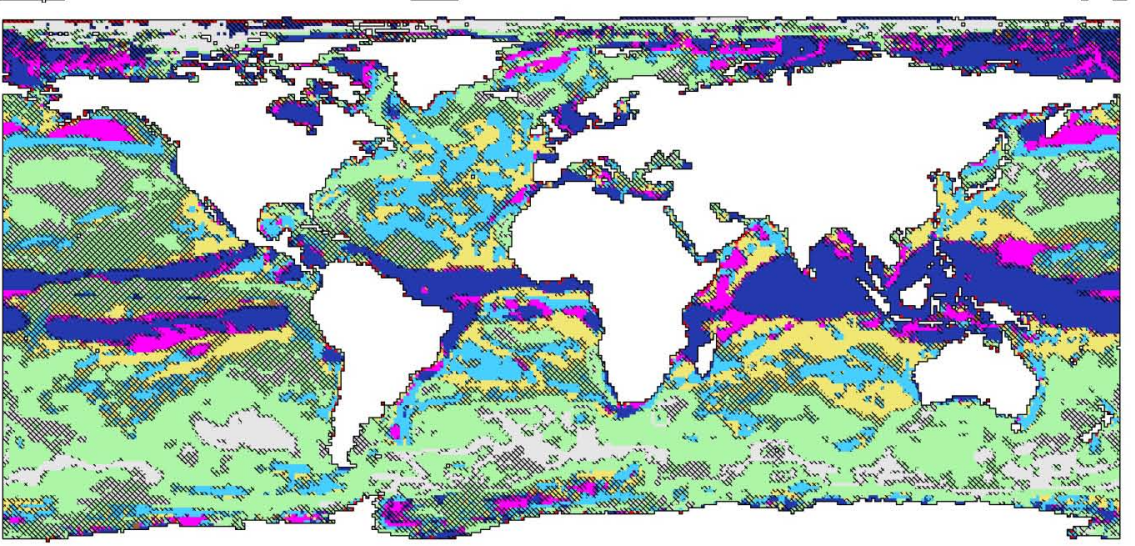

d

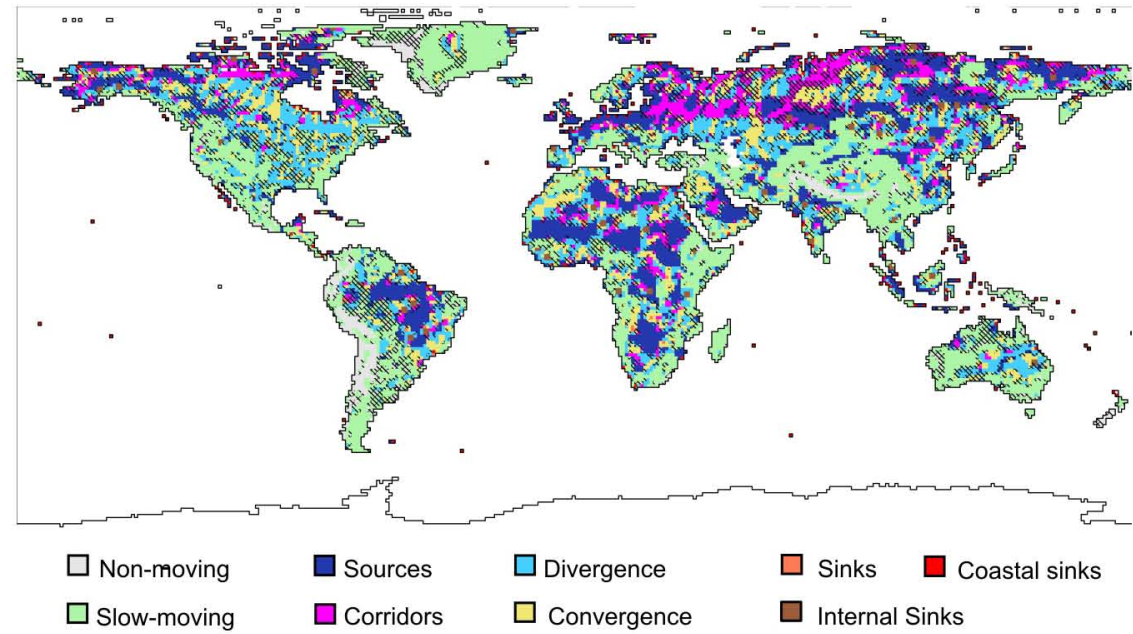

Extended Data Figure 4 | Global patterns of climate-velocity trajectory classes for ocean and land surface temperatures. a-d, Ocean surface temperatures $(\mathbf{a}, \mathbf{c})$ and land surface temperatures $(\mathbf{b}, \mathbf{d})$. Uncertainty in classification of areas is shown by the cross hatching on areas of original global patterns with 500 bootstrap class maps that are classified as 'very likely' (a, b; $<90 \%$ consistency) and 'likely' (c, d; $<66 \%$ consistency). 


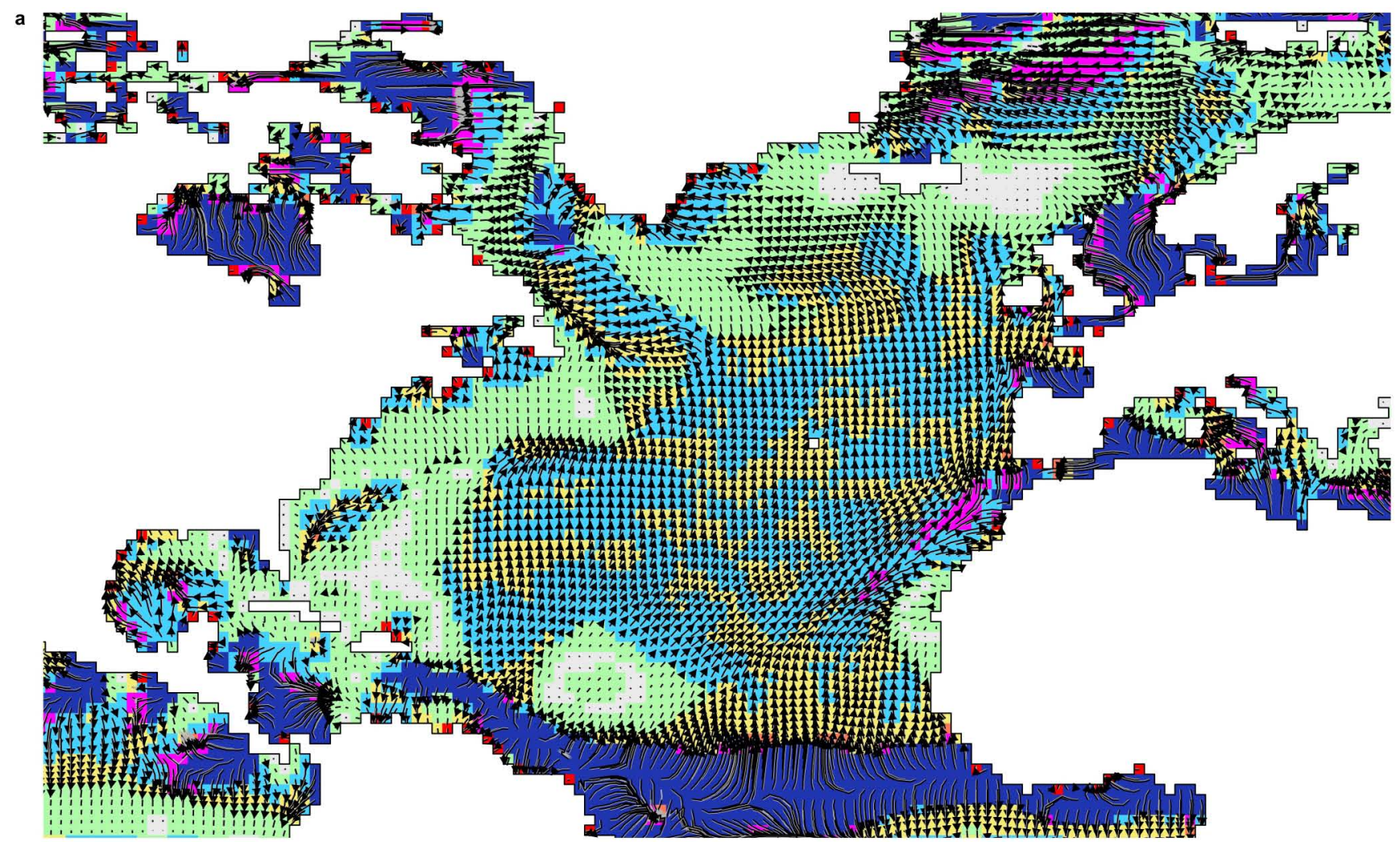

b

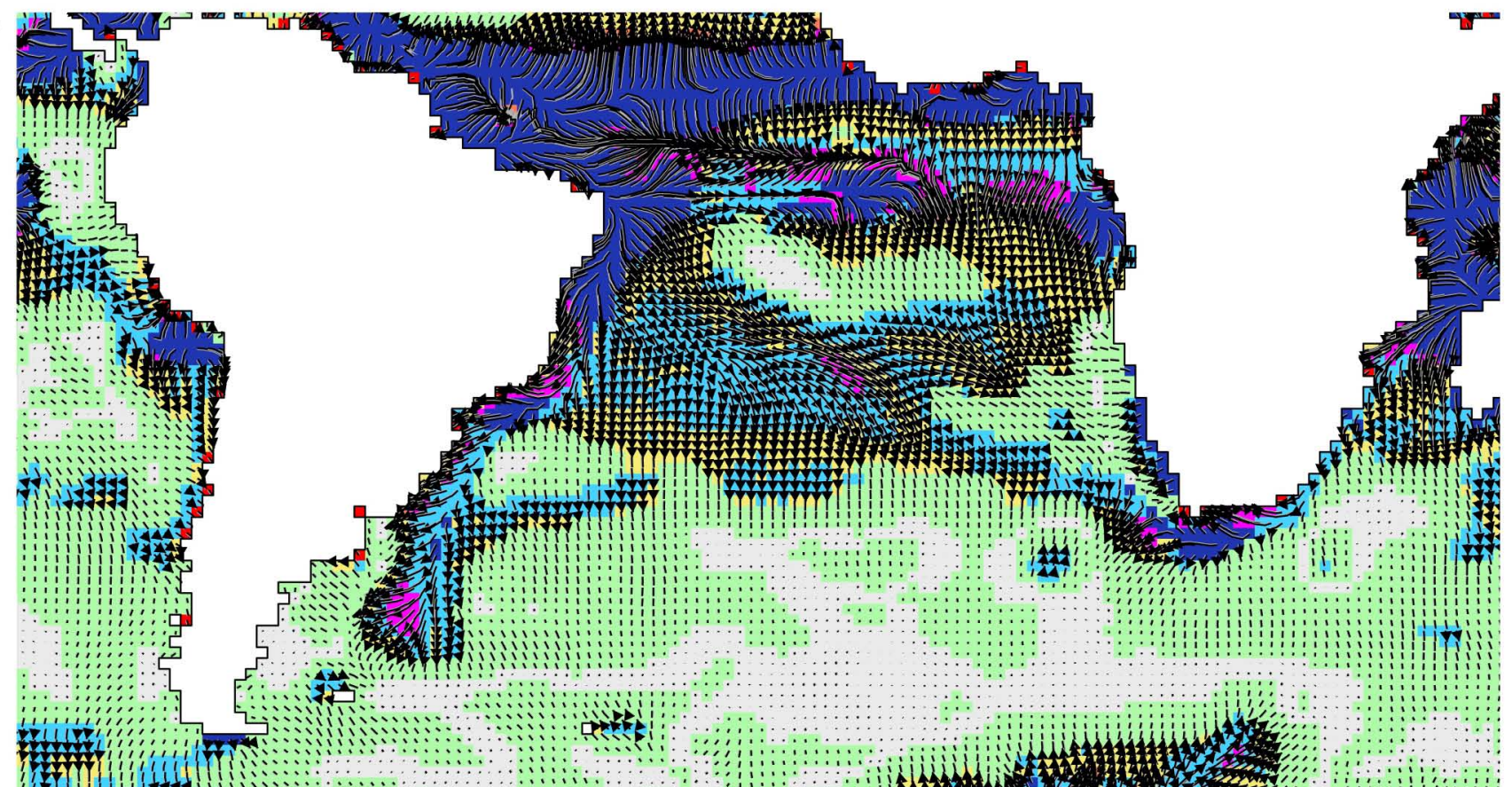
$\square$ Non-moving
$\square$ Sources
$\square$ Divergence
$\square$ Sinks
$\square$ Slow-moving
$\square$ Corridors
$\square$ Convergence
$\square$ Internal Sinks

Extended Data Figure 5 Regional maps for the North and South Atlantic showing 50-year trajectories for the period 1960-2009. a, North
Atlantic b, South Atlantic. Trajectories are overlaid on corresponding classes of trajectory behaviour (Fig. 1). 

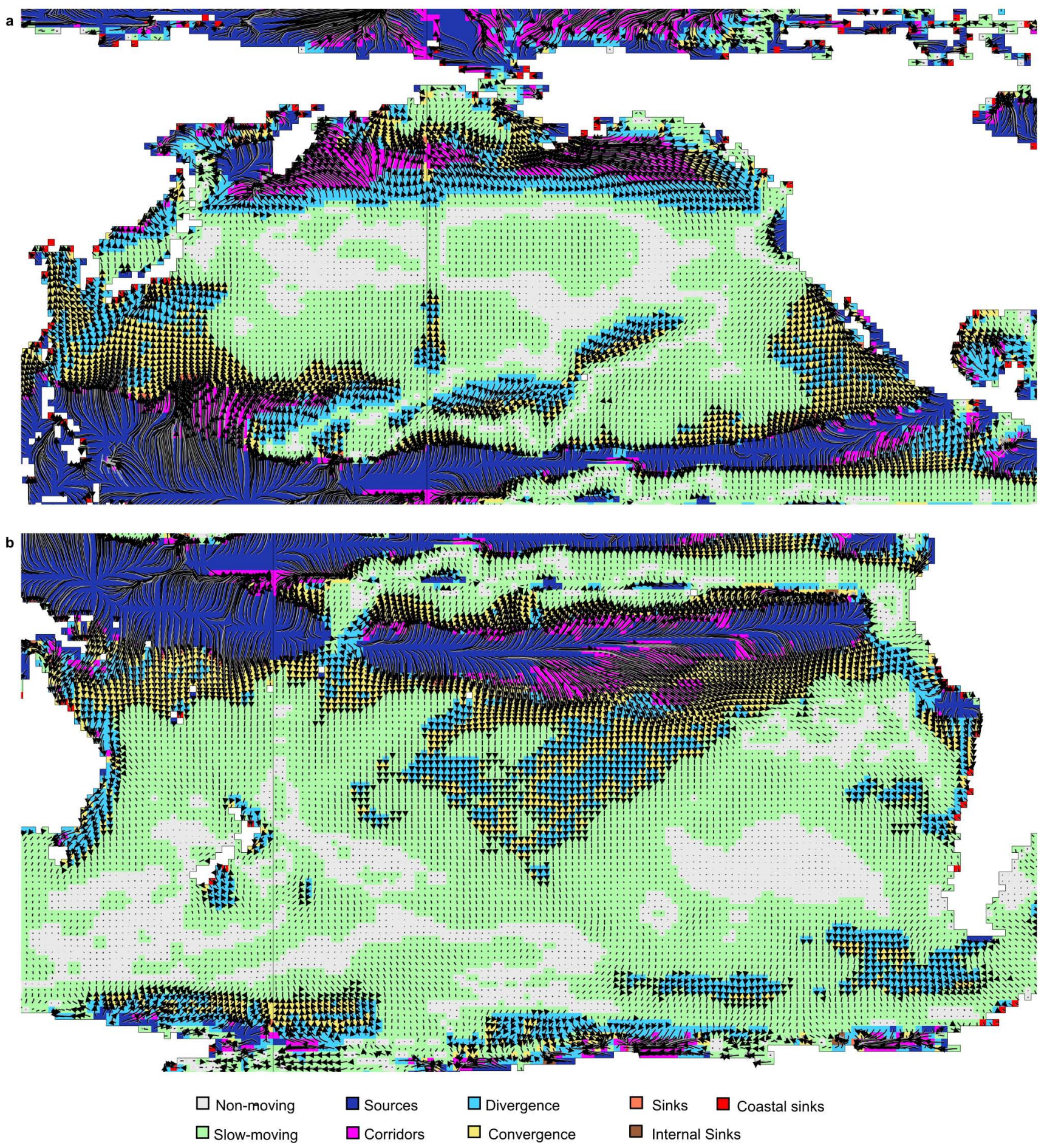

Extended Data Figure 6 | Regional maps for the North and South Pacific showing 50-year trajectories for the period 1960-2009. a, North Pacific. b, South Pacific. Trajectories are overlaid on corresponding classes of trajectory behaviour (Fig. 1). 


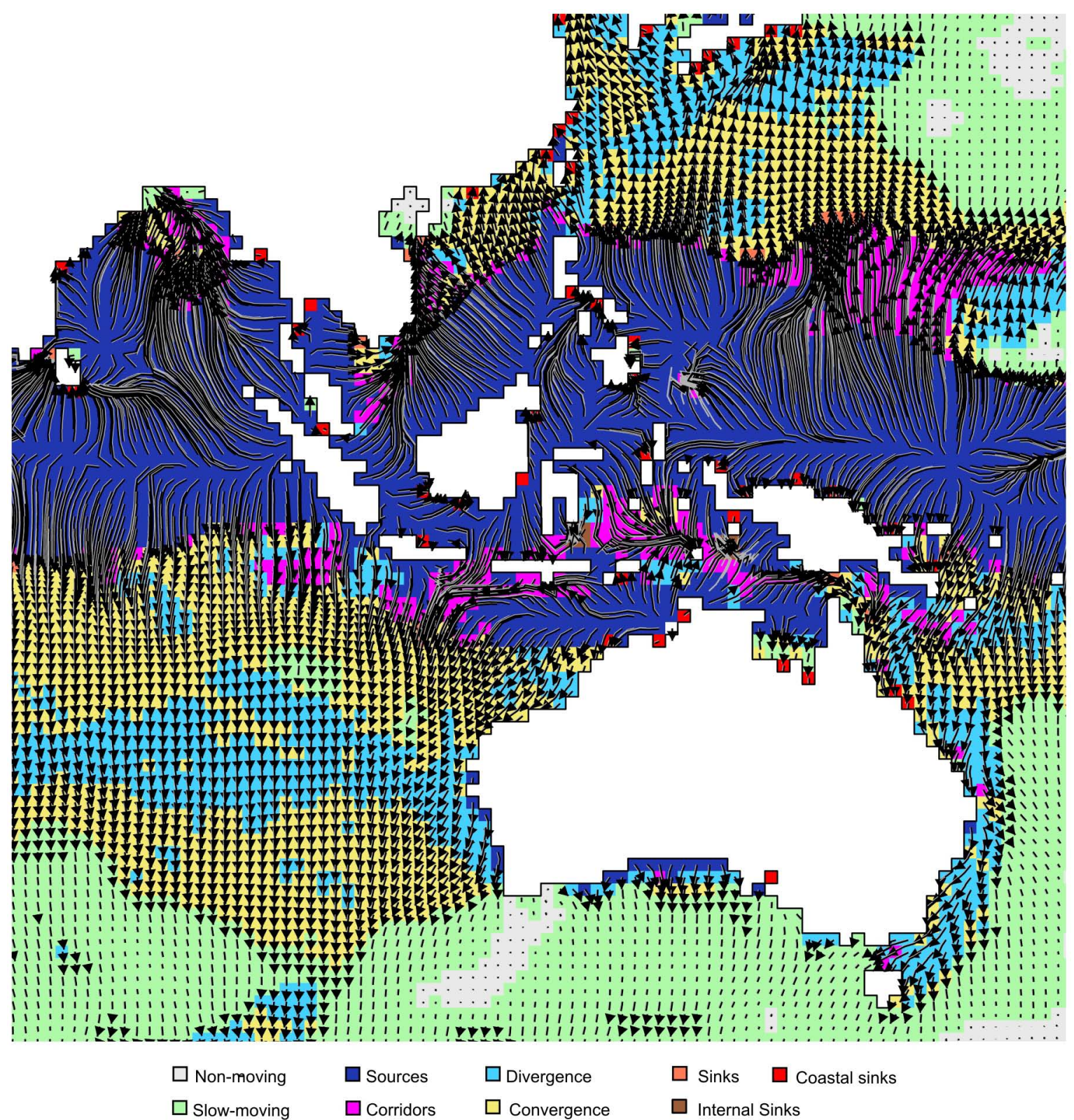

Extended Data Figure $7 \mid$ Regional map for the Coral Triangle showing 50-year trajectories for the period 1960-2009. Trajectories are overlaid on corresponding classes of trajectory behaviour (Fig. 1). 


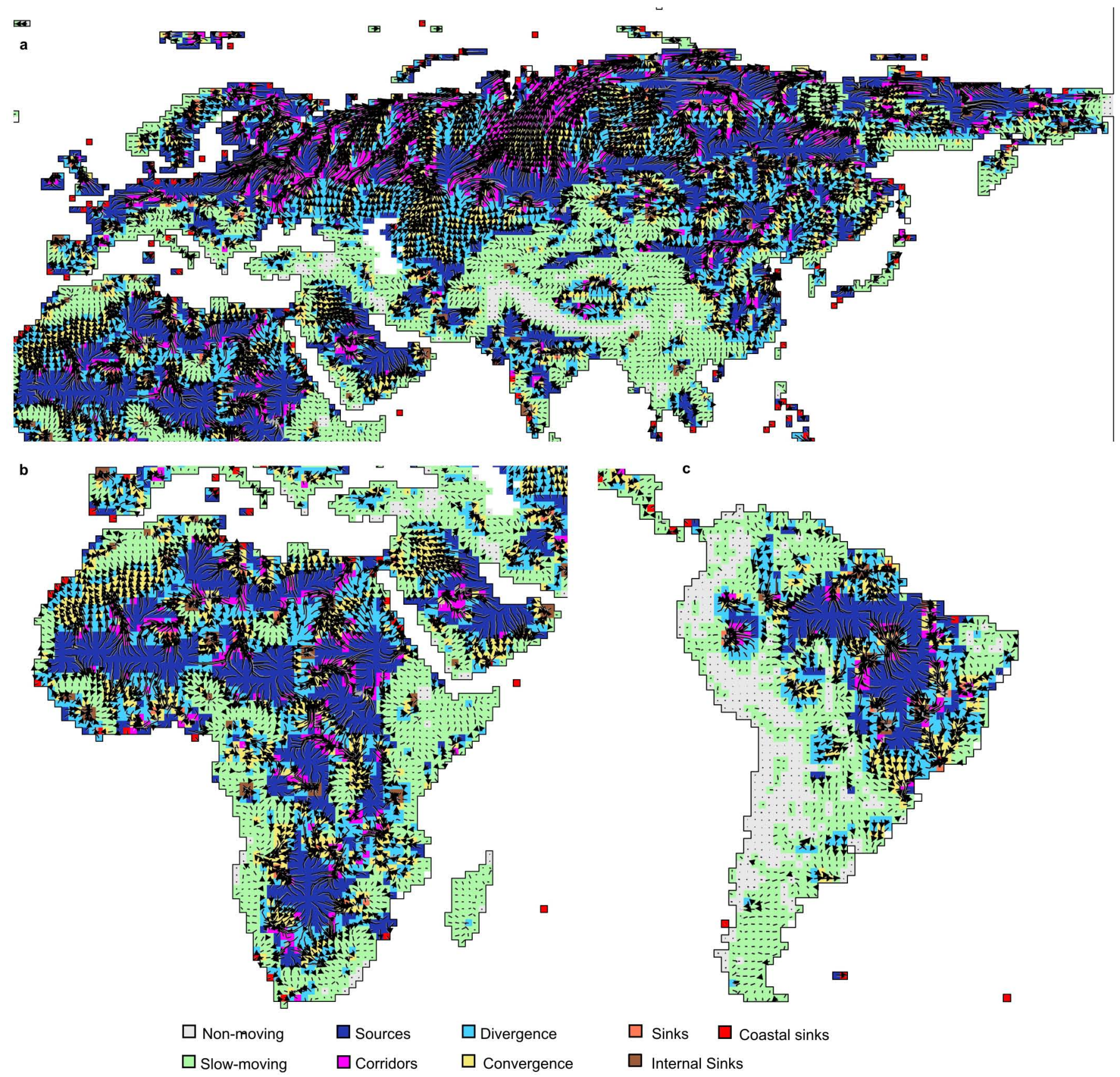

Extended Data Figure $8 \mid$ Regional maps for Eurasia, Africa and South

b, Africa. c, South America. Trajectories are overlaid on corresponding America showing 50-year trajectories for the period 1960-2009. a, Eurasia. trajectory classes of trajectory behaviour (Fig. 1). 


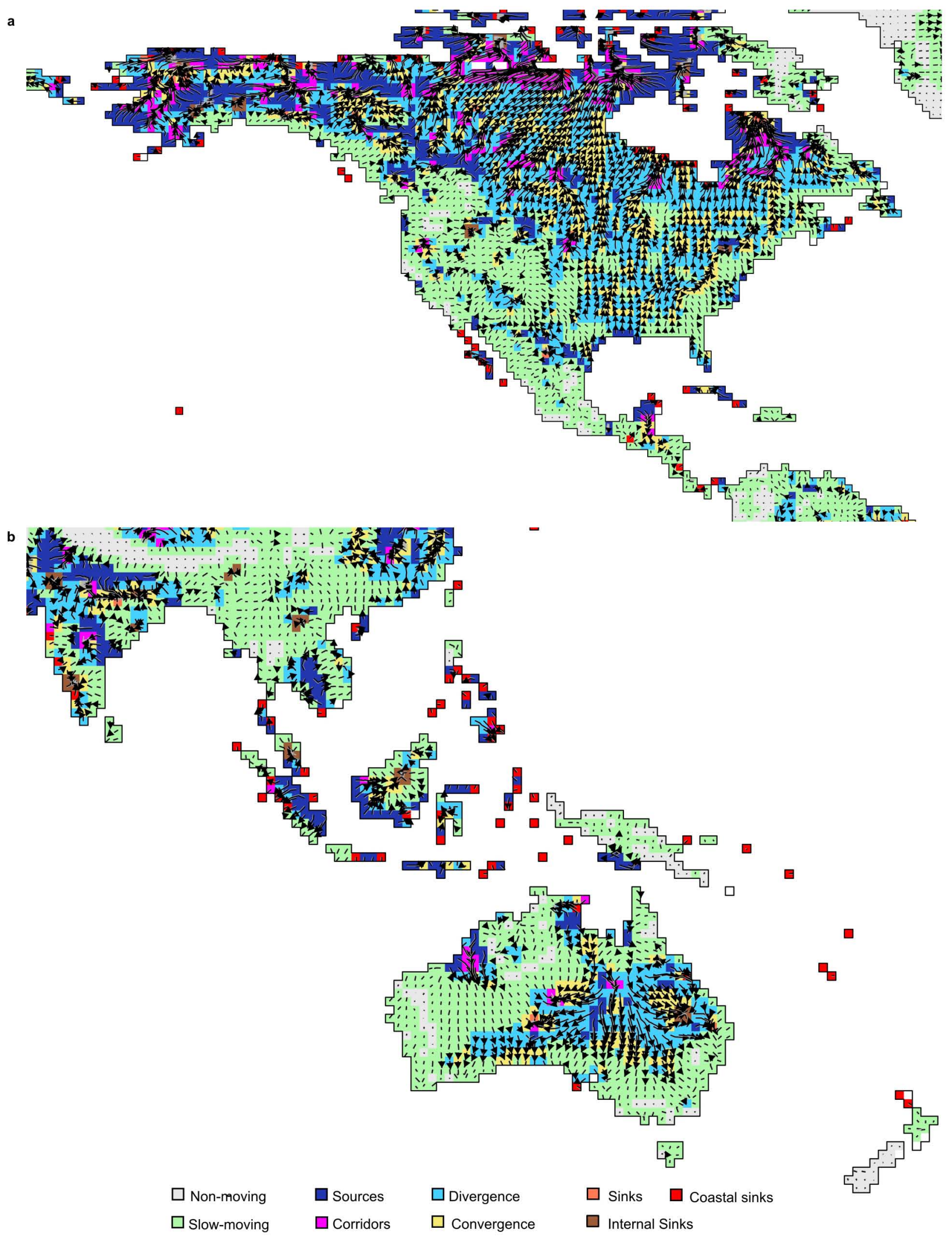

Extended Data Figure $9 \mid$ Regional maps for North and Central America, 1960-2009. a, North and Central America. b, Southeast Asia and Oceania. and southeast Asia and Oceania showing 50-year trajectories for the period Trajectories overlaid on corresponding classes of trajectory behaviour (Fig. 1). 


\section{RESEARCH LETTER}

Extended Data Table 1 | Summary of trajectory classes, with implications for species range shifts if species distributions track shifting climatic niches

Trajectory Class $\quad$ Effects on populations and distributions Effects on species richness
Climate connectivity
$[\%$ consistent]

\begin{tabular}{lll}
\hline Climate Sources & Leading edges cannot invade & $\begin{array}{l}\text { Species richness declines as climate emigrants } \\
\text { not replaced }\end{array}$ \\
Disconnected from warmer locales & High climate emigration, & Empty niches for invaders \\
\hline$>80 \%]$ & No climate immigration & E
\end{tabular}

\section{Climate Sinks}

Disconnected from cooler locales

$$
\begin{gathered}
\text { [Coastal }>60 \% \\
\text { Internal }>30 \% \text { ] }
\end{gathered}
$$

\section{Climate Corridors}

Pathways of strong/intense isotherm movement

$[>60 \%]$

\section{Convergence / Divergence}

Areas where isotherms gather and slow, or speed up and disperse

[>50\%]

\section{Low-velocity areas}

Climate change does not propagate rapidly across the surface

[>80\%]
Species have no adjacent cooler place to relocate

Trailing edges may disappear

No climate emigration, high climate immigration

Species arriving from geographically distinct locations

Increased and novel interactions among species

High emigration and immigration

Areas for rapid shifts

Moderate emigration and immigration

Little, or slow change in distributions
Local extinction possible, but lost species replaced

Richness stable

\section{Richness stable or increased}

Increased effects of species interactions on richness

Richness change depends on balance of migrants

Little change 